\title{
Association of Chronic Stress with Agency, Theory of Mind Function and Abstract Construal in Women
}

\author{
Desmond D. Mascarenhas \\ Mayflower Organization for Research \& Education, Sunnyvale, CA, USA \\ Email: desmond2@mayflowerworld.org
}

How to cite this paper: Mascarenhas, D. D. (2016). Association of Chronic Stress with Agency, Theory of Mind Function and Abstract Construal in Women. Psychology, 7, 1397-1401

http://dx.doi.org/10.4236/psych.2016.712140

Received: August 24, 2016

Accepted: October 31, 2016

Published: November 3, 2016

Copyright $\odot 2016$ by author and Scientific Research Publishing Inc. This work is licensed under the Creative Commons Attribution International License (CC BY 4.0).

http://creativecommons.org/licenses/by/4.0/

\begin{abstract}
Stress disrupts the medial prefrontal cortex (PFC) networks required for consciousness, abstract construal, self-referential thinking, reward circuitry and theory-ofmind functions. We used stress assessment inventories to survey a cohort of 113 women for self-reported stress over a 5 - 10-year period. We identified two subsets of women consistently reporting either high $(n=21)$ or low $(n=24)$ stress over this period. These cohorts answered the eSAIL, REM and Apathy Evaluation Scale questionnaires. Significant differences were found between cohorts in apathy and REM scores, as well as in RD, self-agency and abstraction, but not in other subscales of the eSAIL.
\end{abstract}

\section{Keywords}

Chronic Stress, eSAIL, Innovation, Theory-of-Mind, Abstract Construal

\section{Introduction}

Although recent work has begun to address psychometric correlates of innovation and entrepreneurship (Mascarenhas, Singh, Singh, \& Veer, 2007; Mascarenhas \& Singh, 2012; Mascarenhas \& Veer, 2014; Steel, Rinne, \& Fairweather, 2012; Geels, 2004), the real-life impact of chronic stress on the underlying cognitive and motivational variables is not well understood. Stress affects core circuits in the medial prefrontal cortex (Goldwater, Pavlides, Hunter, Bloss, Hof, McEwen, \& Morrison, 2009; Shansky \& Morrison, 2009) that subserve consciousness (Marino, Bonanno, \& Giorgio, 2015), theoryof-mind functions (Baetens, Ma, Steen, \& Van Overwalle, 2014; Isoda \& Noritake, 2013), humor (Franklin \& Adams, 2011), level of construal (Gilead, Liberman, \& Maril, 2014), intentional stance (Spunt, Meyer, \& Lieberman, 2015) and reward valence as- 
sessment (Hogeveen, Hauner, Chau, Krueger, \& Grafman, 2016).

The Stress-6 questionnaire is a 6-item subset of the previously validated PSS-10 stress inventory (Cohen, Kamarck, \& Mermelstein, 1983). The eSAIL is a 43-item questionnaire that has recently been employed in the assessment of geographical innovation (Mascarenhas \& Singh, 2012) and early adoption of new treatments within the medical profession (Mascarenhas, Singh, Singh, \& Veer, 2007). One of its composite subscales, $\mathrm{RD}$, has been used to measure innovation in women and avant-garde preferences in literature (Mascarenhas \& Veer, 2014). In this study we additionally employ subscales of the eSAIL to measure abstract construal and self-agency.

As a control for agency, we use a reciprocal scale, the Apathy Evaluation Scale (AES), which has been previously described (Clarke, Reekum, Simard, Streiner, Freedman, \& Conn, 2007; Yuen, Gunning, \& Woods, 2014). To measure affective theory-of-mind functions, we use the widely employed and previously validated REM test (Olderbak, Wilhelm, Olaru, Geiger, Brenneman, \& Roberts, 2015).

\section{Research Aims}

This work aims to measure the impacts of chronic stress on psychometric measures relevant to innovation and entrepreneurship while helping construct a hypothetical framework for future neuropsychological research in this area.

\section{Methods}

\subsection{Participants and Settings}

A subset of a previously reported cohort was used in this study. All participants provided informed consent and the study protocol was approved by the Institutional Review Board. Procedures for online data collection from the original 1277 anonymous adult participants have been described in three previously published studies using the eSAIL, a 43-item online inventory for which satisfactory Cronbach alpha and test-retest reliability coefficients have been observed for all component psychometric scales, while discriminant, convergent, and predictive validities have been shown across cohorts (Mascarenhas, Singh, Singh, \& Veer, 2007).

\subsection{Procedure}

113 individuals from the original cohort who scored high ( $>0.3 \mathrm{SD}$ above mean) or low $(<0.3$ SD below mean) scores in the STRESS subscale of the eSAIL in 2005 or 2010 additionally answered the STRESS-6 in 2014 and 2015, and the REM, AES and AGENCY inventories in 2015. Two subsets of women consistently reporting either high $(\mathrm{n}=21)$ or low $(n=24)$ stress in all three stress inventories over either the 5 or 10 -year period were combined for data analysis.

\subsection{Measures}

\subsubsection{STRESS-6 Questionnaire}

The STRESS-6 questionnaire is a six-item subset of a previously validated stress inven- 
tory (Cohen, Kamarck, \& Mermelstein, 1983).

\subsection{2. eSAIL and Subscales Thereof}

The eSAIL subscale RD has been used to measure innovation in women and avantgarde preferences in literature (Mascarenhas \& Veer, 2014). The following eSAIL subscales used in the current study were originally designed to measure attributes believed to relate to innovation and entrepreneurship: plasticity/rigidity (IMPROMPTU, DOGMATIC), internal/external locus of control (BOLD, RESPBIAS), optimism/pessimism (POSITIVE, MACH), stress (STRESS) and abstraction (ABSTRACT) (Mascarenhas, Singh, Singh, \& Veer, 2007). The RD composite measure was derived by averaging $\mathrm{z}$ values for RESPBIAS and DOGMATIC scores and reversing the direction of the resulting scale (Mascarenhas \& Veer, 2014). Similarly, the five-item AGENCY subscale is a composite of the POSITIVE and BOLD sub-scales of the eSAIL (Mascarenhas, Singh, Singh, \& Veer, 2007). Cronbach alpha for AGENCY was 0.683, with alphas for one missing item ranging from 0.59 to 0.68 . As a negative control for agency, a reciprocal scale was used, the AES, which has been previously described (Clarke, Reekum, Simard, Streiner, Freedman, \& Conn, 2007). In this study the ABSTRACT subscale of the eSAIL was employed to evaluate habitual preference for abstract construal (Gilead, Liberman, \& Maril, 2014).

\subsubsection{REM Test}

To measure affective theory-of-mind functions, the widely used and previously described and validated REM test was employed (Olderbak, Wilhelm, Olaru, Geiger, Brenneman, \& Roberts, 2015).

\subsection{Data Analysis}

Data are presented as means \pm SD. Probability values ( $p$ values) were computed using Student's $t$-test.

\section{Results}

Table 1 shows a number of significant differences between the two cohorts. As expected, the Persistent High Stress group scored significantly higher than the Persistent Low Stress group in the STRESS subscale of the eSAIL, as well as in the STRESS-6 inventory.

Table 1. Chronic stress and average Z scores".

\begin{tabular}{cccc}
\hline Scale & Persistent Low Stress & Persistent High Stress & $p$ Value \\
\hline STRESS $^{*}$ & $-0.83 \pm 0.34$ & $1.30 \pm 0.55$ & $<0.0001$ \\
STRESS-6 & $-1.15 \pm 0.36$ & $1.14 \pm 0.41$ & $<0.0001$ \\
AGENCY-2 $^{*}$ & $1.14 \pm 0.45$ & $-0.31 \pm 1.13$ & $<0.0001$ \\
APATHY & $25.50 \pm 4.70$ & $33.62 \pm 5.71$ & $<0.0001$ \\
REM & $28.04 \pm 2.97$ & $25.81 \pm 3.43$ & 0.0257 \\
RD $^{*}$ & $0.57 \pm 0.72$ & $0.04 \pm 0.98$ & 0.0469 \\
ABSTRACT $^{*}$ & $0.03 \pm 0.66$ & $-0.52 \pm 0.91$ & 0.0269 \\
\hline
\end{tabular}

${ }^{*}$ Subscale of the eSAIL; ${ }^{*}$ Population mean $=0$. 
The High Stress group showed significantly lower AGENCY-2 scores and significantly higher AES scores than the Low Stress group. Cognitive scores for affective theory-of-mind (REM), innovation (RD) and abstract construal (ABSTRACT) were also significantly lower in the High Stress group.

In contrast, the IMPROMPTU and MACH subscale scores of the eSAIL showed no significant differences between groups.

\section{Discussion}

\subsection{Chronic Stress and Psychometric Data}

The results reported here show a significant association of chronic stress with reduced agency, innovation, abstraction and mentalizing functions. As the data are correlational, it is not possible to deduce a causal association. Nevertheless there is a substantial body of literature demonstrating the impact of stress on brain circuits such as the medial PFC "default network" and reward circuitry of the vmPFC (Goldwater, Pavlides, Hunter, Bloss, Hof, McEwen, \& Morrison, 2009; Shansky \& Morrison, 2009). These circuits are believed to subserve the functions listed above, as referenced in the Introduction section.

\subsection{Implications and Limitations}

This is a preliminary finding in a small cohort. A larger study will be needed to confirm these initial observations. The practical implications of this finding, if confirmed by future studies, are potentially significant for innovation management. The link between psychometric scales and innovation is supported by published data (Mascarenhas, Singh, Singh, \& Veer, 2007; Mascarenhas \& Singh, 2012; Mascarenhas \& Veer, 2014; Steel, Rinne, \& Fairweather, 2012; Geels, 2004). Taken together, these facts may suggest the increasing importance of resilience to stress in the management of knowledge economy within which shorter product cycles create a growing dependence on innovation.

\section{References}

Baetens, K., Ma, N., Steen, J., \& Van Overwalle, F. (2014). Involvement of the Mentalizing Network in Social and Non-Social High Construal. Social Cognitive Affect Neuroscience, 9, 817824. http://dx.doi.org/10.1093/scan/nst048

Clarke, D. E., Reekum, R., Simard, M., Streiner, D. L., Freedman, M., \& Conn, D. (2007). Apathy in Dementia: An Examination of the Psychometric Properties of the Apathy Evaluation Scale. The Journal of Neuropsychiatry and Clinical Neurosciences, 19, 57-64. http://dx.doi.org/10.1176/jnp.2007.19.1.57

Cohen, S., Kamarck, T., \& Mermelstein, R. (1983). A Global Measure of Perceived Stress. Journal of Health and Social Behavior, 24, 385-396. http://dx.doi.org/10.2307/2136404

Franklin Jr., R. G., \& Adams Jr., R.B. (2011). The Reward of a Good Joke: Neural Correlates of Viewing Dynamic Displays of Stand-Up Comedy. Cognitive Affect Behavioral Neuroscience, 11, 508-515. http://dx.doi.org/10.3758/s13415-011-0049-7

Geels, F. W. (2004). From Sectoral Systems of Innovation to Socio-Technical Systems: Insights 
about Dynamics and Change from Sociology and Institutional Theory. Research Policy, 33, 897-920. http://dx.doi.org/10.1016/j.respol.2004.01.015

Gilead, M., Liberman, N., \& Maril, A. (2014). From Mind to Matter: Neural Correlates of Abstract and Concrete Mindsets. Social Cognitive Affect Neuroscience, 9, 638-645.

http://dx.doi.org/10.1093/scan/nst031

Goldwater, D. S., Pavlides, C., Hunter, R. G., Bloss, E. B., Hof, P. R., McEwen, B. S., \& Morrison, J. H. (2009). Structural and Functional Alterations to Rat Medial Prefrontal Cortex Following Chronic Restraint Stress and Recovery. Neuroscience, 164, 798-808.

http://dx.doi.org/10.1016/j.neuroscience.2009.08.053

Hogeveen, J., Hauner, K. K., Chau, A., Krueger, F., \& Grafman, J. (2016). Impaired Valuation Leads to Increased Apathy Following Ventromedial Prefrontal Cortex Damage. Cerebral Cortex, bhv317. First Published Online January 5, 2016. http://dx.doi.org/10.1093/cercor/bhv317

Isoda, M., \& Noritake, A. (2013). What Makes the Dorsomedial Frontal Cortex Active during Reading the Mental States of Others? Frontiers in Neuroscience, 7, 232-240. http://dx.doi.org/10.3389/fnins.2013.00232

Marino, S., Bonanno, L., \& Giorgio, A. (2016). Functional Connectivity in Disorders of Consciousness: Methodological Aspects and Clinical Relevance. Brain Imaging Behavior, 10, 604608. http://dx.doi.org/10.1007/s11682-015-9417-1

Mascarenhas, D., Singh, B. K., Singh, A.H., \& Veer, S. V. (2007). Early Adoption of New Drug Treatments: The Role of Continuing Medical Education and physician Adaptivity. Critical Pathways in Cardiology, 6, 30-40. http://dx.doi.org/10.1097/01.hpc.0000257844.53130.d0

Mascarenhas, D., \& Singh, A. H. (2012). Regional Culture and Adaptive Behavior of Physicians. Journal of Bioeconomics, 14, 257-266. http://dx.doi.org/10.1007/s10818-011-9115-Z

Mascarenhas, D. D., \& Veer, S. V. (2014). Women, Innovation and Literature. Journal of Innovation and Entrepreneurship, 3, 7. http://dx.doi.org/10.1186/2192-5372-3-7

Olderbak, S., Wilhelm, O., Olaru, G., Geiger, M., Brenneman, M. W., \& Roberts, R. D. (2015). A Psychometric Analysis of the Reading the Mind in the Eyes Test: Toward a Brief Form for Research and Applied Settings. Frontiers in Psychology, 6, 1503-1508. http://dx.doi.org/10.3389/fpsyg.2015.01503

Shansky, R. M., \& Morrison, J. H. (2009). Stress-Induced Dendritic Remodeling in the Medial Prefrontal Cortex: Effects of Circuit, Hormones and Rest. Brain Research, 1293, 108-113. http://dx.doi.org/10.1016/j.brainres.2009.03.062

Spunt, R. P., Meyer, M. L., \& Lieberman, M. D. (2015). The Default Mode of Human Brain Function Primes the Intentional Stance. Journal of Cognitive Neuroscience, 27, 1116-1124. http://dx.doi.org/10.1162/jocn_a_00785

Steel, G. D., Rinne, T., \& Fairweather, J. (2012). Personality, Nations, and Innovation: Relationships between Personality Traits and National Innovation Scores. Cross-Cultural Research, 46, 3-8. http://dx.doi.org/10.1177/1069397111409124

Yuen, G. S., Gunning, F. M., \& Woods, E. (2014). Neuroanatomical Correlates of Apathy in LateLife Depression and Antidepressant Treatment Response. Journal of Affective Disorders, 166, 179-186. http://dx.doi.org/10.1016/j.jad.2014.05.008 
Submit or recommend next manuscript to SCIRP and we will provide best service for you:

Accepting pre-submission inquiries through Email, Facebook, LinkedIn, Twitter, etc. A wide selection of journals (inclusive of 9 subjects, more than 200 journals)

Providing 24-hour high-quality service

User-friendly online submission system

Fair and swift peer-review system

Efficient typesetting and proofreading procedure

Display of the result of downloads and visits, as well as the number of cited articles

Maximum dissemination of your research work

Submit your manuscript at: http://papersubmission.scirp.org/

Or contact psych@scirp.org 